\title{
Retraction
}

\section{Retracted: Type-2 Fuzzy Logic Controller of a Doubly Fed Induction Machine}

\author{
Advances in Fuzzy Systems \\ Received 4 December 2017; Accepted 4 December 2017; Published 15 May 2018 \\ Copyright (C) 2018 Advances in Fuzzy Systems. This is an open access article distributed under the Creative Commons Attribution \\ License, which permits unrestricted use, distribution, and reproduction in any medium, provided the original work is properly \\ cited.
}

Advances in Fuzzy Systems has retracted the article titled "Type-2 Fuzzy Logic Controller of a Doubly Fed Induction Machine" [1]. The article was previously published as "Loukal Keltoum, Benalia Leila, "Type-2 Fuzzy Logic Control of a Doubly-Fed Induction Machine (DFIM)," International Journal of Artificial Intelligence, Vol 4, No 4, 2015. http:// iaescore.com/journals/index.php/IJAI/article/view/6125 [2].

The authors say they did not approve final publication in International Journal of Artificial Intelligence and they do not support the retraction. The IJAI Editor-in-Chief said this was the responsibility of journal staff, but the journal and publisher did not respond to our queries.

\section{References}

[1] K. Loukal and L. Benalia, "Type-2 fuzzy logic controller of a doubly fed induction machine," Advances in Fuzzy Systems-Applications and Theory, vol. 2016, Article ID 8273019, pp. 1-10, 2016.

[2] L. Keltoum and B. Leila, "Type-2 fuzzy logic control of a doublyfed induction machine (DFIM)," International Journal of Artificial Intelligence, vol. 4, no. 4, 2015, http://iaescore.com/journals/ index.php/IJAI/article/view/6125. 


\title{
Type-2 Fuzzy Logic Controller of a Doubly Fed Induction Machine
}

\author{
Keltoum Loukal and Leila Benalia
}

LGE Research Laboratory, Department of Electrical Engineering, Faculty of Technology, Mohamed Boudiaf University of M'sila, BP 166, Ichbilia, 28000 M'sila, Algeria

Correspondence should be addressed to Keltoum Loukal; muohtlek@yahoo.fr

Received 24 October 2015; Revised 22 December 2015; Accepted 29 December 2015

Academic Editor: Mehmet Onder Efe

Copyright (C) 2016 K. Loukal and L. Benalia. This is an open access article distributed under the Creative Commons Attribution License, which permits unrestricted use, distribution, and reproduction in any medium, provided the original work is properly cited.

Interval type-2 fuzzy logic controller (IT2FLC) method for controlling the speed with a direct stator flux orientation control of doubly fed induction motor (DFIM) is proposed. The fuzzy controllers have demonstrated their effectiveness in the control of nonlinear systems, and in many cases it is proved that their robustness and performance are less sensitive to parameters variation over conventional controllers. The synthesis of stabilizing control laws design based on IT2FLC is developed. A comparative analysis between type-1 fuzzy logic controller (T1FLC) and IT2FLC of the DFIM is shown. Simulation results show the feasibility and the effectiveness of the suggested method to the control of the DFIM under different operating conditions such as load torque and in the presence of parameters variation.

\section{Introduction}

Since the early years of industrialization, the researchers were faced with "how to control the electric machines at variable speed." Electric drives require high performance, increased reliability, and reduced cost. Among these machines, doubly fed induction machine (DFIM) [1-3] is an asynchronous machine with wound rotor which can be supplied at the same time by the stator and the rotor with external source voltages [4]. It was first studied to be used as a high-speed motor. The many benefits of this machine are reduced manufacturing cost, relatively simple construction, higher speed, and not requiring ongoing maintenance. In recent decades, with the advances in technology of power electronics and microcomputer, different applications of DFIM became possible. Their interest lies mainly in the speed control options with and without mechanical sensors as well as the regimes in either motor or generator operations with flux control powers for hypo- and hypersynchronous features [5]. For operation at different speeds a converter PWM (Pulse Width Modulation) must be inserted between the machine and the network. Whatever the speed of the machine, the voltage is rectified and an inverter connected to the network side is responsible for ensuring consistency between the network frequency and that delivered by the device. The DFIM is essentially nonlinear, due to the coupling between the flux and the electromagnetic torque. The vector control or field orientation control allows a decoupling between the torque and the flux $[6,7]$.

With the field orientation control (FOC) method, induction machine drives are becoming a major candidate in high-performance motion control applications, where servo quality operation is required. Fast transient response is made possible by decoupled torque and flux control. The most widely used control method is perhaps the proportional integral control (PI). It is easy to design and implement, but it has difficulty in dealing with parameter variations and load disturbances [8]. Recent literature has paid much attention to the potential of fuzzy control in machine drive applications.

In the area of control of electrical machinery, research is increasingly oriented towards the application of modern control techniques. These techniques are involved with the evolution of computers and power electronics. This enables leading manufacturers to high-performance processes. These techniques are linear control [1], sliding mode control [1, 4], feedback linearization, adaptive control, and fuzzy control 


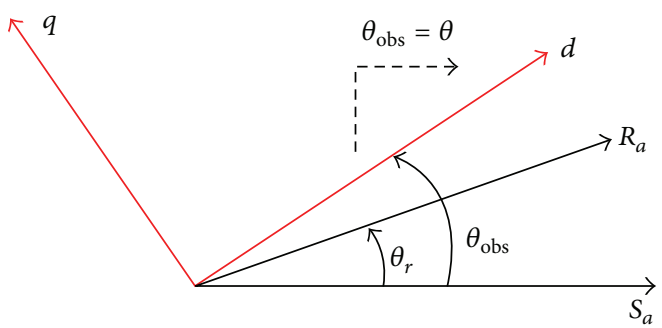

FIGURE 1: Defining the real axes of DFIM from the reference $(d, q)$.

[9]. This last fuzzy logic controller (FLC) usually gives better results for nonlinear systems with variable parameters. The DFIM is an ideal candidate for testing the performance of fuzzy logic controllers [10]. Conventional type-1 fuzzy logic system can be used to identify the behavior of this highly nonlinear system with various types of uncertainties. However, type-1 fuzzy sets cannot fully capture the uncertainties in the system due to the imprecision of membership functions and knowledge base; thus, higher types of fuzzy sets have to be considered. It is clear that the computational complexity of operations on fuzzy sets increases with the increasing type of the fuzzy set. In this work, for their simplicity and efficiency to capture the severe nonlinearities of the DFIM, the interval type-2 fuzzy sets will be used. Till now, type- 2 fuzzy logic systems have been used in very few control applications such as nonlinear control and the speed control of machines. Nevertheless, it is still possible to achieve robustness and highly efficient dynamics using a control technique that does not need a detailed model. This is the case with the controller presented herein where an interval type- 2 fuzzy logic controller is designed to achieve the speed stabilization of DFIM. The present work deals with an interval type- 2 fuzzy logic controller (IT2FLC) method for controlling the speed of DFIM in a vector control mode.

The paper is organized as follows. In Section 2 mathematical model of the DFIM is presented. In Section 3, we begin with the DFIM oriented model in view of the vector control; next the stator flux $\phi_{s}$ is estimated. A number of controllers based artificial intelligence is introduced in Section 4. Interval type-2 fuzzy logic systems and a type- 2 fuzzy inference engine are presented in Section 5 and the design procedure of the proposed controller with the simulation results is given in Section 6. Finally, some conclusions are drawn in Section 7.

\section{Description and Modeling of DFIM}

In the training of high power as the rolling mill, there is a new and original solution using a double feed induction motor (DFIM). The stator is feed by a fixed network and the rotor by a variable supply which can be either a voltage or current source.

The electrical model of the DFIM presented in Figure 1 is expressed in a $(d-q)$ synchronous rotating frame.
2.1. Reference Fixed Relative to the Rotating Field $(d, q)$. For a reference related to the rotating field, the following electrical equations are deduced:

$$
\begin{aligned}
{\left[\begin{array}{c}
V_{s d} \\
V_{s q}
\end{array}\right]=} & {\left[\begin{array}{cc}
R_{s} & 0 \\
0 & R_{s}
\end{array}\right]\left[\begin{array}{c}
I_{s d} \\
I_{s q}
\end{array}\right]+\frac{d}{d t}\left[\begin{array}{c}
\Phi_{s d} \\
\Phi_{s q}
\end{array}\right] } \\
& +\left[\begin{array}{cc}
0 & -\omega_{s} \\
\omega_{s} & 0
\end{array}\right]\left[\begin{array}{c}
\Phi_{s d} \\
\Phi_{s q}
\end{array}\right], \\
{\left[\begin{array}{c}
V_{r d} \\
V_{r q}
\end{array}\right]=} & {\left[\begin{array}{cc}
R_{r} & 0 \\
0 & R_{r}
\end{array}\right]\left[\begin{array}{c}
I_{r d} \\
I_{r q}
\end{array}\right]+\frac{d}{d t}\left[\begin{array}{c}
\Phi_{r d} \\
\Phi_{r q}
\end{array}\right] } \\
& +\left[\begin{array}{cc}
0 & -\omega \\
\omega & 0
\end{array}\right]\left[\begin{array}{l}
\Phi_{r d} \\
\Phi_{r q}
\end{array}\right],
\end{aligned}
$$

where $I_{s}, I_{r}, V_{s}$, and $V_{r}$ denote stator currents, rotor currents, stator terminal voltage, and rotor terminal voltage, respectively. The subscripts $s$ and $r$ stand for stator and rotor while subscripts $d$ and $q$ stand for vector component with respect to a fixed stator reference frame [12].

Expressions of flux are given by

$$
\begin{aligned}
& \phi_{s d}=l_{s} I_{s d}+M I_{r d}, \\
& \phi_{s q}=l_{s} I_{s q}+M I_{r q}, \\
& \phi_{r d}=l_{r} I_{r d}+M I_{s d}, \\
& \phi_{r q}=l_{r} I_{r q}+M I_{s q} .
\end{aligned}
$$

$\phi_{s}, \phi_{r}, l_{s}, l_{r}$, and $M$ denote stator flux, rotor flux, stator inductance, rotor inductance, and mutual inductance, respectively.

Replacing (2) with (1) we obtained

$$
\begin{aligned}
& V_{s d}=R_{s} I_{s d}+l_{s} \frac{d I_{s d}}{d t}+M \frac{d I_{r d}}{d t}-\omega_{s} l_{s} I_{s q}-\omega_{s} M I_{r q}, \\
& V_{s q}=R_{s} I_{s q}+l_{s} \frac{d I_{s q}}{d t}+M \frac{d I_{r q}}{d t}+\omega_{s} l_{s} I_{s d}+\omega_{s} M I_{r d}, \\
& V_{r d}=R_{r} I_{r d}+l_{r} \frac{d I_{r d}}{d t}+M \frac{d I_{s d}}{d t}-\omega l_{r} I_{r q}-\omega M I_{s q}, \\
& V_{r q}=R_{r} I_{r q}+l_{r} \frac{d I_{r q}}{d t}+M \frac{d I_{s q}}{d t}+\omega l_{r} I_{r d}+\omega M I_{s d},
\end{aligned}
$$


where $\omega_{s}, \omega, R_{s}$, and $R_{r}$ denote stator pulsation, rotor pulsation, stator resistance, and rotor resistance, respectively.

2.2. DFIM Model in the Form of State Equation. For the DFIM the control variables are the stator and rotor voltages [10] by considering the following:

(i) An input-output current decoupling is set for all currents.

(ii) The $(d-q)$ frame is oriented with the stator flux.

(iii) Due to the large gap between the mechanical and electrical time constants, the speed can be considered as invariant with respect to the state vector.

Under these conditions, the electrical equations of the machine are described by a time variant state space system as shown in

$$
\begin{aligned}
& \dot{X}=A \cdot X+B \cdot U, \\
& Y=C \cdot X
\end{aligned}
$$

where $X, A, B, U, Y$, and $C$ represent the state vector, system state evolution matrix, matrix of control, vector of the control system, output vector, and output matrix (observation matrix), respectively, where

$$
\begin{aligned}
& X=\left[\begin{array}{llll}
i_{s d} & i_{s q} & i_{r d} & i_{r q}
\end{array}\right]^{T}, \\
& U=\left[\begin{array}{lllll}
V_{s d} & V_{s q} & V_{r d} & V_{r q}
\end{array}\right]^{T},
\end{aligned}
$$

using the frequently adopted assumptions, like sinusoid ally distributed air-gap flux density distribution and linear magnetic conditions, and considering the stator voltages $\left(V_{s d}, V_{s q}\right)$ and rotor voltages $\left(V_{r d}, V_{r q}\right)$ as control inputs and the stator current $\left(I_{s d}, I_{s q}\right)$ and the rotor current $\left(I_{r d}, I_{r q}\right)$ as state variables.

From a matrix representation,

$$
\begin{aligned}
& \frac{d}{d t}\left[\begin{array}{c}
I_{s d} \\
I_{s q} \\
I_{r d} \\
I_{r q}
\end{array}\right]=\left[\begin{array}{cccc}
L_{s} & 0 & M & 0 \\
0 & L_{s} & 0 & M \\
M & 0 & L_{r} & 0 \\
0 & M & 0 & L_{r}
\end{array}\right]^{-1}\left[\begin{array}{cccc}
-R_{s} & \omega_{s} L_{s} & 0 & \omega_{s} M \\
-\omega_{s} L_{s} & -R_{s} & -\omega_{s} M & 0 \\
0 & \left(\omega_{s}-\omega\right) M & -R_{s} & \left(\omega_{s}-\omega\right) L_{r} \\
-\left(\omega_{s}-\omega\right) M & 0 & -\left(\omega_{s}-\omega\right) L_{r} & -R_{s}
\end{array}\right]\left[\begin{array}{c}
I_{s d} \\
I_{s q} \\
I_{r d} \\
I_{r q}
\end{array}\right] \\
& +\left[\begin{array}{cccc}
L_{s} & 0 & M & 0 \\
0 & L_{s} & 0 & M \\
M & 0 & L_{r} & 0 \\
0 & M & 0 & L_{r}
\end{array}\right]^{-1}\left[\begin{array}{c}
V_{s d} \\
V_{s q} \\
V_{r d} \\
V_{r q}
\end{array}\right]
\end{aligned}
$$

Let

$$
[L]=\left[\begin{array}{cccc}
L_{s} & 0 & M & 0 \\
0 & L_{s} & 0 & M \\
M & 0 & L_{s} & 0 \\
0 & M & 0 & L_{s}
\end{array}\right],
$$

$[Z]$

$$
=\left[\begin{array}{cccc}
-R_{s} & \omega_{s} L_{s} & 0 & \omega_{s} M \\
-\omega_{s} L_{s} & -R_{s} & -\omega_{s} M & 0 \\
0 & \left(\omega_{s}-\omega\right) M & -R_{s} & \left(\omega_{s}-\omega\right) L_{r} \\
-\left(\omega_{s}-\omega\right) M & 0 & -\left(\omega_{s}-\omega\right) L_{r} & -R_{s}
\end{array}\right] .
$$

Then (4) becomes

$$
\frac{d X}{d t}=[L]^{-1} \cdot[Z] \cdot X+[L]^{-1} \cdot U
$$

In analogy to (8) with (4) we find $A=[L]^{-1} \cdot[Z]$ and $B=[L]^{-1}$ [12]:

$$
\begin{aligned}
A & =\left[\begin{array}{cccc}
-a_{1} & a \omega+\omega_{s} & a_{3} & a_{5} \omega \\
-a \omega-\omega_{s} & -a_{1} & -a_{5} \omega & a_{3} \\
a_{4} & -a_{6} \omega & -a_{2} & -\frac{\omega}{\sigma}+\omega_{s} \\
a_{6} \omega & a_{4} & \frac{\omega}{\sigma}-\omega_{s} & -a_{2}
\end{array}\right], \\
B & =\left[\begin{array}{cccc}
b_{1} & 0 & -b_{3} & 0 \\
0 & b_{1} & 0 & -b_{3} \\
-b_{3} & 0 & b_{2} & 0 \\
0 & -b_{3} & 0 & b_{2}
\end{array}\right]
\end{aligned}
$$

$$
C=\left[\begin{array}{llll}
1 & 0 & 0 & 0 \\
0 & 1 & 0 & 0 \\
0 & 0 & 1 & 0 \\
0 & 0 & 0 & 1
\end{array}\right],
$$


where

$$
\begin{aligned}
& a=\frac{1-\sigma}{\sigma}, \\
& a_{1}=\frac{R_{s}}{\sigma L_{s}}, \\
& a_{2}=\frac{R_{r}}{\sigma L_{r}}, \\
& a_{3}=\frac{R_{r} M}{\sigma L_{s} L_{r}}, \\
& a_{4}=\frac{R_{s} M}{\sigma L_{s} L_{r}}, \\
& a_{5}=\frac{M}{\sigma L_{s}}, \\
& a_{6}=\frac{M}{\sigma L_{r}}, \\
& b_{1}=\frac{1}{\sigma L_{s}}, \\
& b_{2}=\frac{1}{\sigma L_{r}}, \\
& b_{3}=\frac{M}{\sigma L_{s} L_{r}}, \\
& \sigma=1-\frac{M^{2}}{L_{s} L_{r}} .
\end{aligned}
$$

$L_{s}$ and $L_{r}$ are stator and rotor cyclic inductances; $\sigma$ is redefined leakage factor [10].

The generated torque of DFIM can be expressed in terms of stator currents and stator flux linkage as

$$
C_{e}=\frac{P M}{L_{s}}\left(\phi_{s q} \cdot i_{r d}-\phi_{s d} \cdot i_{r q}\right) .
$$

$P$ is number of pole pairs. In addition, the mechanical dynamic equation is given by

$$
J \frac{d \Omega}{d t}=C_{e}-C_{r}-f \Omega .
$$

$J, C_{e}, C_{r}$, and $f$ denote the moment inertia of the motor, the electromagnetic torque, the external load torque, and viscous friction coefficient, respectively. $\Omega$ is the mechanical speed.

\section{Vector Control by Direct Stator Flux Orientation}

To simplify the control we need to make a judicious choice reference. For this, we place ourselves in a reference $(d, q)$ related to the rotating field with an orientation of the flux stator, according to the condition of the stator flux orientation $[14,15]$ :

$$
\begin{aligned}
& \phi_{s d}=\phi_{s}, \\
& \phi_{s q}=0 .
\end{aligned}
$$

By replacing (13) with (1) we obtain

$$
\begin{aligned}
V_{s d} & =R_{s} I_{s d}, \\
V_{s q} & =R_{s} I_{s q}+\omega_{s} \phi_{s d}, \\
V_{r d} & =R_{r} I_{r d}-\omega \phi_{r q}, \\
V_{r q} & =R_{r} I_{r q}+\omega \phi_{r d} \\
& \mathbb{I} \\
\phi_{s q} & =0 \Longrightarrow I_{s q}=-\frac{M}{L_{s}} I_{r q}, \\
I_{s d} & =0, \\
I_{r d} & =\frac{\phi_{s}^{*}}{M} .
\end{aligned}
$$

The torque equation becomes

$$
\begin{aligned}
& C_{e}=-\frac{P M}{L_{s}} \phi_{s}^{*} \cdot I_{r q}, \\
& I_{r q}=-\frac{L_{s}}{P \cdot M \cdot \phi_{s}^{*}} \cdot C_{e}{ }^{*} .
\end{aligned}
$$

Equation (3) was

$$
\frac{d \theta_{s}}{d t}=\omega_{s}=\frac{\left(R_{s} M / L_{s}\right) I_{r q}+V_{s q}}{\phi_{s}^{*}} .
$$

According to (2) of the stator flux, then

$$
\begin{aligned}
& I_{s d}=\frac{1}{L_{s}}\left(\phi_{s d}-M I_{r d}\right), \\
& I_{s q}=\frac{1}{L_{s}}\left(\phi_{s q}-M I_{r q}\right) .
\end{aligned}
$$

From relations (17) and (3),

$$
\begin{aligned}
& \dot{\phi}_{s d}=V_{s d}+\frac{M}{T_{s}} I_{r d}-\frac{1}{T_{s}} \phi_{s d}, \\
& \dot{\phi}_{s q}=V_{s q}+\frac{M}{T_{s}} I_{r q}-\omega_{s} \phi_{s q} .
\end{aligned}
$$

The relationship of the rotor current is

$$
\begin{aligned}
\dot{I}_{r d}= & -\frac{1}{\sigma}\left(\frac{1}{T_{r}}+\frac{M^{2}}{L_{s} T_{s} L_{r}}\right) I_{r d}-\frac{M}{\sigma L_{s} L_{r}} V_{s d} \\
& +\frac{M}{\sigma L_{r} L_{s} T_{s}} \phi_{s d}+\left(\omega_{s}-\omega\right) I_{r q}+\frac{1}{\sigma L_{r}} V_{r d}, \\
\dot{I}_{r q}= & -\frac{1}{\sigma}\left(\frac{1}{T_{r}}+\frac{M^{2}}{L_{s} T_{s} L_{r}}\right) I_{r q}-\frac{M}{\sigma L_{s} L_{r}} V_{s q} \\
& +\frac{M}{\sigma L_{r} L_{s}} \omega \phi_{s d}-\left(\omega_{s}-\omega\right) I_{r d}+\frac{1}{\sigma L_{r}} V_{r q} .
\end{aligned}
$$


The relationship of the mechanical speed is

$$
\frac{d \Omega}{d t}=\frac{P \cdot M}{J \cdot L_{s}}\left(I_{r q} \cdot \phi_{s d}\right)-\frac{C_{r}}{J}-\frac{f}{J} \Omega,
$$

where $T_{s}=L_{s} / R_{s}$ and $T_{r}=L_{r} / R_{r}$ are stator and rotor time constants, respectively [10].

3.1. Stator Flux Estimator. In the direct vector control stator flux oriented DFIM, precise knowledge of the amplitude and the position of the stator flux vector is necessary. In motor mode of DFIM, the stator and rotor currents are measured whereas the stator flux can be estimated [10]. The flux estimation may be obtained by the following equations:

$$
\begin{aligned}
& \phi_{s d}=l_{s} I_{s d}+M I_{r d}, \\
& \phi_{s q}=l_{s} I_{s q}+M I_{r q} .
\end{aligned}
$$

The position stator flux is calculated by the following equations:

$$
\theta_{r}=\theta_{s}-\theta
$$

in which

$$
\begin{gathered}
\theta_{s}=\int \omega_{s} d t \\
\theta=\int \omega d t .
\end{gathered}
$$

$\omega=P \cdot \Omega$ and $\theta_{s}$ is the electrical stator position; $\theta$ is the electrical rotor position.

\section{Context of Type-2 Fuzzy Logic Controller}

The classic fuzzy logic now called type-1 has been generalized to a new type of fuzzy logic called fuzzy logic-2. In recent years, Mendel et al. [16, 17] and their colleagues have been working on this new logic; they have built a theoretical basis and demonstrated its effectiveness and superiority to type1 fuzzy logic. This is new class of type 2 fuzzy systems in which the principle of membership values is sort of fuzzy1 sets. Type- 2 fuzzy sets are very effective in circumstances where it is difficult to determine accurately the membership functions for fuzzy sets; therefore, they are very effective for incorporating uncertainties [13].

The concept of fuzzy sets type-2 was introduced by Zadeh et al. $[13,18,19]$ as an extension of the ordinary fuzzy set concept called fuzzy-type-1. Type-2 fuzzy set is characterized by a fuzzy membership function; that is, the value of membership (membership degree) of each element of the set is a fuzzy set in $[0,1]$. Such sets can be used in situations where we have uncertainty about the values of the same membership. Uncertainty can be in the form of either the membership function or one of its parameters [13].

Consider the transition from normal sets to fuzzy sets. When we cannot determine the degree of membership of an element with a set of 0 or 1 , using fuzzy sets type- 1 and the fuzzy membership functions by real numbers in $[0,1]$,

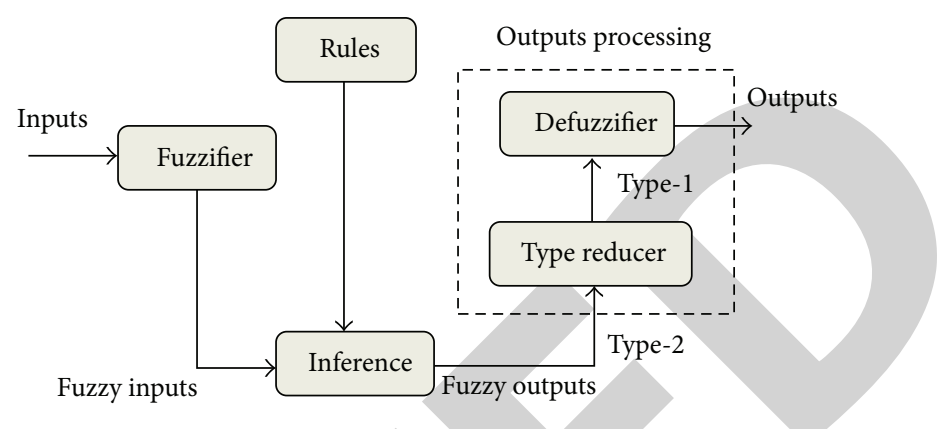

FIgURE 2: Structure of type-2 fuzzy logic system [13].

then we use fuzzy sets type-2. So ideally we need to use fuzzy sets type- $\infty$ to complete the representation of uncertainty. Of course, we cannot realize this in practice, because we have to use fuzzy sets of finite type. Therefore, type- 1 fuzzy sets can be considered as a first-order approximation of uncertainty, while type-2 fuzzy sets will be considered as a second-order approximation [13].

Type-2 fuzzy sets are generalized forms of those of type-1 (with the FOU as an additional degree of freedom). Mathematically, a type- 2 fuzzy set, denoted as $\widetilde{A}$, is characterized by a type- 2 membership function $\mu_{\widetilde{A}}(x, u)$, where $x \in X$ and $u \in J_{x} \subseteq[0,1]$ : that is,

$$
\widetilde{A}=\left\{(x, u) \mu_{\widetilde{A}}(x, u) \quad \forall x \in X, \forall u \in J_{x} \subseteq[0,1]\right\}
$$

in which $0 \leq \mu_{\widetilde{A}}(x, u) \leq 1$. For a continuous universe of discourse, $\widetilde{A}$ can be expressed as

$$
\widetilde{A}=\int_{x \in X} \int_{u \in J_{x}} \frac{\mu_{\widetilde{A}}(x, u)}{(x, u)} \quad J_{x} \subseteq[0,1],
$$

where $J_{x}$ is referred to as the primary membership of $x$. As in type-1 fuzzy logic, discrete fuzzy sets are represented by the symbol $\sum$ instead of $\int$. The secondary membership function associated with $x=x^{\prime}$, for a given $x^{\prime} \in X$, is type-1 membership function defined by $\mu_{\widetilde{A}}\left(x=x^{\prime}, u\right), \forall u \in J_{x}$.

The structure of a fuzzy system type- 2 is shown in Figure 2.

4.1. Type-2 Membership Functions. Type-2 fuzzy logic systems are characterized by the form of their membership functions. Figure 3 shows two different membership functions: (a) a typical type-1 membership function and (b) a blurred type1 membership function that represents a type- 2 membership function.

The uncertainty in the primary membership of a type-2 fuzzy set $\widetilde{A}$ is represented by the FOU and is illustrated in Figure $3(\mathrm{~b})$. Note that the FOU is also the union of all primary memberships:

$$
\operatorname{FOU}(\widetilde{A})=\bigcup_{x \in X} J_{x}
$$

The upper and lower membership functions, denoted by $\bar{\mu}_{\widetilde{A}}(x)$ and $\underline{\mu}_{\widetilde{A}}(x)$, respectively, are two type-1 membership 


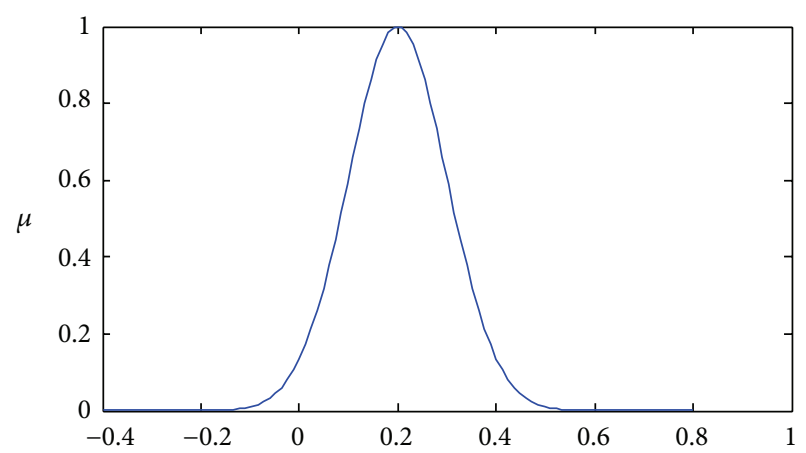

(a)

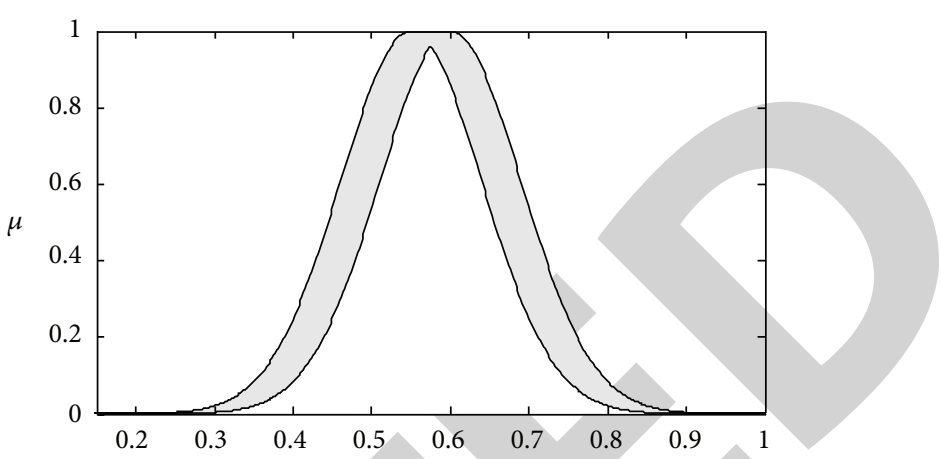

(b)

FIgURE 3: (a) Type-1 membership function and (b) footprint of uncertainty.

functions that represent the upper and lower bounds for the footprint of uncertainty of an interval type- 2 membership function $\mu_{\widetilde{A}}(x, u)$, respectively [20].

4.2. Fuzzifier. The membership function type- 2 gives several degrees of membership for each input. Therefore, the uncertainty will be more represented. This representation allows us to take into account what has been overlooked by type-1. The fuzzifier maps the input vector $\left(e_{1}, e_{2}, \ldots, e_{n}\right)^{T}$ onto a type-2 fuzzy system $\widetilde{A}_{x}$, very similar to the procedure performed in a type-1 fuzzy logic system.

4.3. Rules. The general form of the $i$ th rule of type- 2 fuzzy logic system can be written as

$$
\begin{aligned}
& \text { If } e_{1} \text { is } \widetilde{F}_{1}^{i} \text { and } e_{2} \text { is } \widetilde{F}_{2}^{i} \text { and } e_{n} \text { is } \widetilde{F}_{n}^{i} \text {, then } y^{i}=\widetilde{G}^{i} \\
& i=1, \ldots, M \text {, } \\
& > \\
& \checkmark, \ldots, M,
\end{aligned}
$$

where $\widetilde{F}_{j}^{i}$ represent type-2 fuzzy system of the input state $j$ of the $i$ th rule, $x_{1}, x_{2}, \ldots, x_{n}$ are the inputs, $\widetilde{G}^{i}$ is the output of type-2 fuzzy system for the rule $i$, and $M$ is the number of rules. As can be seen, the rule structure of type-2 fuzzy logic system is similar to type-1 fuzzy logic system except that type-1 membership functions are replaced with their type- 2 counterparts.

4.4. Inference Engine. In fuzzy system interval type-2 using the minimum or product $\mathrm{t}$-norms operations, the $i$ th activated rule $F^{i}\left(x_{1}, \ldots x_{n}\right)$ gives us the interval that is determined by two extremes, $\underline{f}^{i}\left(x_{1}, \ldots x_{n}\right)$ and $\bar{f}^{i}\left(x_{1}, \ldots x_{n}\right)[21]$ :

$$
\begin{aligned}
F^{i}\left(x_{1}, \ldots x_{n}\right) & =\left[\underline{f}^{i}\left(x_{1}, \ldots x_{n}\right), \bar{f}^{i}\left(x_{1}, \ldots x_{n}\right)\right] \\
& \equiv\left[\underline{f}^{i}, \bar{f}^{i}\right]
\end{aligned}
$$

where $\underline{f}^{i}$ and $\bar{f}^{i}$ are given as

$$
\begin{aligned}
& \underline{f}^{i}=\underline{\mu}_{F_{1}^{i}}\left(x_{1}\right) * \cdots * \underline{\mu}_{F_{n}^{i}}\left(x_{n}\right), \\
& \bar{f}^{i}=\bar{\mu}_{F_{1}^{i}}\left(x_{1}\right) * \cdots * \bar{\mu}_{F_{n}^{i}}\left(x_{n}\right) .
\end{aligned}
$$

4.5. Type Reducer. After the rules are fired and inference is executed, the obtained type-2 fuzzy system resulting in type1 fuzzy system is computed. In this part, the available methods to compute the centroid of type-2 fuzzy system using the extension principle [17] are discussed. The centroid of type-1 fuzzy system $A$ is given by

$$
C_{A}=\frac{\sum_{i=1}^{n} z_{i} w_{i}}{\sum_{i=1}^{n} w_{i}}
$$

where $n$ represents the number of discretized domains of $A$, $z_{i} \in R$, and $w_{i} \in[0,1]$. If each $z_{i}$ and $w_{i}$ are replaced with a type-1 fuzzy system, $Z_{i}$ and $W_{i}$, with associated membership functions of $\mu_{Z}\left(z_{i}\right)$ and $\mu_{W}\left(W_{i}\right)$, respectively, by using the extension principle, the generalized centroid for type- 2 fuzzy system $\widetilde{A}$ is given by

$$
\begin{aligned}
& G C_{\widetilde{A}} \\
& =\int_{z_{1} \in Z_{1}} \ldots \int_{z_{n} \in Z_{n}} \int_{w_{1} \in W_{1}} \ldots \int_{w_{n} \in W_{n}} \frac{\left[T_{i=1}^{n} \mu_{Z}\left(z_{i}\right) * T_{i=1}^{n} \mu_{W}\left(z_{i}\right)\right]}{\sum_{i=1}^{n} z_{i} w_{i} / \sum_{i=1}^{n} w_{i}} .
\end{aligned}
$$

$T$ is a t-norm and $G C_{\widetilde{A}}$ is a type- 1 fuzzy system. For an interval type-2 fuzzy system,

$$
\begin{gathered}
G C_{\widetilde{A}}=\left[y_{l}(x), y_{r}(x)\right]=\int_{y^{1} \in\left[y_{l}^{1}, y_{r}^{1}\right]} \ldots \int_{y^{M} \in\left[y_{l}^{M}, y_{r}^{M}\right]} \\
\quad \ldots \int_{f^{1} \in\left[\underline{f}^{1}, \bar{f}^{1}\right]} \ldots \int_{f^{M} \in\left[\underline{f}^{M}, \bar{f}^{M}\right]} \frac{1}{\sum_{i=1}^{M} f^{i} y^{i} / \sum_{i=1}^{M} f^{i}} .
\end{gathered}
$$

4.6. Defuzzifier. To get a crisp output from a type-1 fuzzy logic system, the type-reduced set must be defuzzified. The most common method to do this is to find the centroid of the type-reduced set. If the type-reduced set $Y$ is discretized to $n$ 


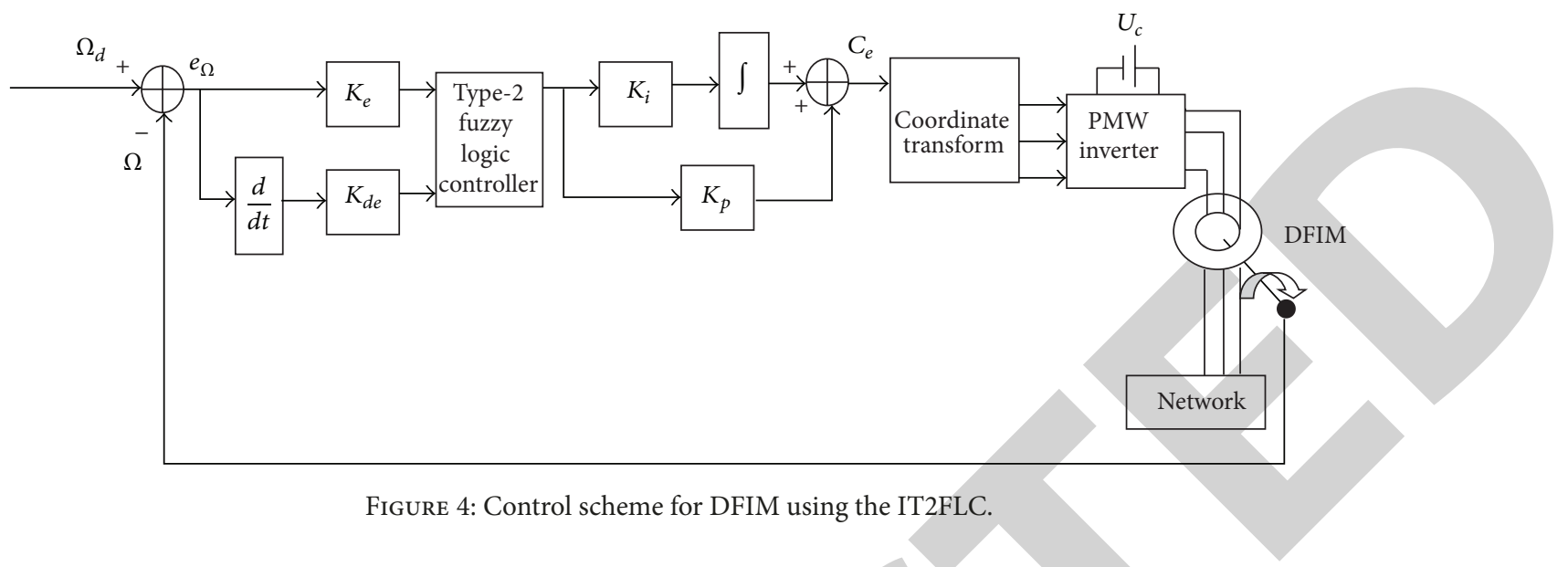

points, then the following expression gives the centroid of the type-reduced set as

$$
y_{\text {output }}(x)=\frac{\sum_{i=1}^{n} y^{i} \mu\left(y^{i}\right)}{\sum_{i=1}^{m} \mu\left(y^{i}\right)} .
$$

We can compute the output using the iterative Karnik Mendel Algorithms [20,22]. Therefore, the defuzzified output of an IT2FLC is

$$
Y_{\text {output }}(x)=\frac{y_{l}(x)+y_{r}(x)}{2}
$$

with

$$
\begin{gathered}
y_{l}(x)=\frac{\sum_{i=1}^{M} f_{l}^{i} y_{l}^{i}}{\sum_{i=1}^{M} f_{l}^{i}}, \\
y_{r}(x)=\frac{\sum_{i=1}^{M} f_{r}^{i} y_{l}^{i}}{\sum_{i=1}^{M} f_{r}^{i}} .
\end{gathered}
$$

\section{Type-2 Fuzzy Controller Design}

In this problem, vector control by direct stator flux orientation is used in the control of the DFIM; the bloc diagram of the speed control was replaced by an IT2FLC. The DFIM system model was simulated first using a conventional T1FLC and then an IT2FLC. The rule base was the same for both type- 1 and type- 2 fuzzy logic controllers. The fuzzy control strategy is based on a human operator experience to interpret a situation and initiate its control action. The IT2FLC used in a vector control of DFIM is presented in Figure 4.

$e_{\Omega}$ and $\Delta e_{\Omega}$ represent the output error and its derivative, respectively. For the speed $\Omega$ the error and its derivative are given by

$$
\begin{aligned}
e_{\Omega}(k) & =\Omega_{d}-\Omega, \\
\Delta e_{\Omega}(k) & =\frac{e_{\Omega}(k+1)-e_{\Omega}(k)}{T},
\end{aligned}
$$

where $T$ and $\Omega_{d}$ are the sampling period and desired speed, respectively.

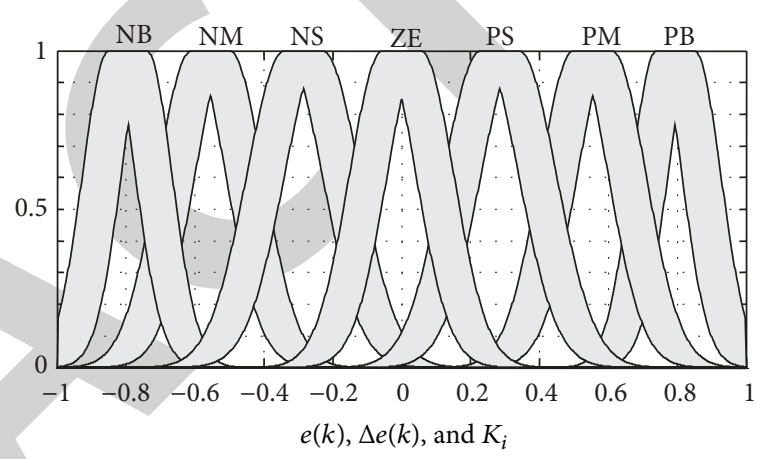

FIgURE 5: Type-2 fuzzy membership functions of the speed error, their variation, and the control signal.

TABLE 1: Fuzzy rules for IT2FLC [11].

\begin{tabular}{lccccccc}
\hline$e(k)$ & & & \multicolumn{7}{c}{$\Delta e(k)$} \\
& NB & NM & NS & ZE & PS & PM & PB \\
\hline NB & NB & NB & NB & NM & NS & NVS & ZE \\
NM & NB & NB & NM & NS & NVS & ZE & PVS \\
NS & NB & NM & NS & NVS & ZE & PVS & PS \\
ZE & NM & NS & NVS & ZE & PVS & PS & PM \\
PS & NS & NVS & ZE & PVS & PS & PM & PB \\
PM & NVS & ZE & PVS & PS & PM & PB & PB \\
PB & ZE & PVS & PS & PM & PB & PB & PB \\
\hline
\end{tabular}

The speed errors, their variation, and the control signal are chosen to be Gaussian identical shapes as indicated in Figure 5. They are quantized into seven levels represented by a set of linguistic variables which are negative big (NB), negative medium (NM), negative small (NS), zero (ZE), positive small (PS), positive medium (PM), and positive big (PB).

In this work, the controller fuzzy rules are gathered in Table 1.

The processed surface is shown in Figure 6. 


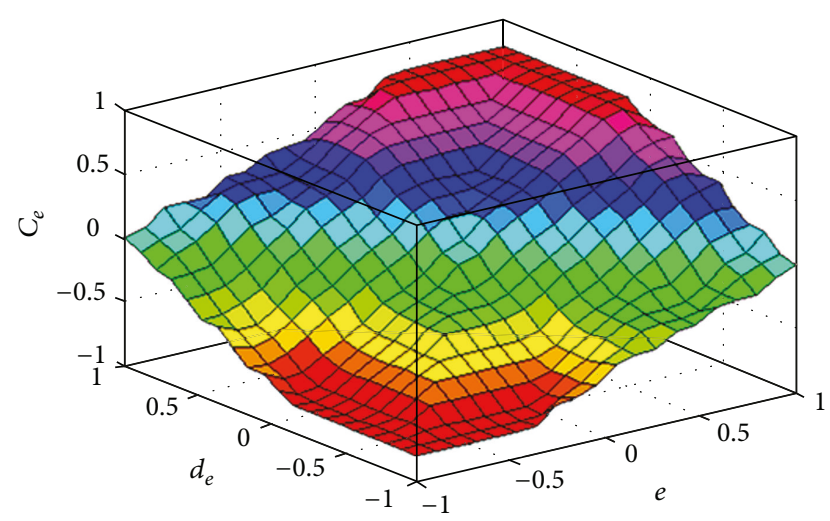

FIgURE 6: Surface for the torque $C_{e}$.

TABLE 2: Parameters of the DFIM [12].

\begin{tabular}{lcc}
\hline Definition & Symbol & Value \\
\hline DFIM mechanical power & $P_{w}$ & $4 \mathrm{~kW}$ \\
Stator voltage & $U_{s n}$ & $380 \mathrm{~V}$ \\
Rotor voltage & $U_{r n}$ & $220 \mathrm{~V}$ \\
Nominal current & $I_{n}$ & $3.8 / 2.2 \mathrm{~A}$ \\
Nominal mechanical speed & $\Omega_{n}$ & $1420 \mathrm{rpm}$ \\
Nominal stator and rotor frequencies & $\omega_{s n}$ & $50 \mathrm{~Hz}$ \\
Pole pairs number & $P$ & 2 \\
Stator resistance & $R_{s}$ & $11.98 \Omega$ \\
Rotor resistance & $R_{r}$ & $0.904 \Omega$ \\
Stator self-inductance & $L_{s}$ & $0.414 \mathrm{H}$ \\
Rotor self-inductance & $L_{r}$ & $0.0556 \mathrm{H}$ \\
Mutual inductance & $M$ & $0.126 \mathrm{H}$ \\
Moment of inertia & $J$ & $0.01 \mathrm{Kg} \cdot \mathrm{m}^{2}$ \\
Friction coefficient & $f$ & $0.00 \mathrm{IS}$ \\
\hline
\end{tabular}

\section{Simulation and Results}

Several simulations have been run using the MATLAB and Simulink ${ }^{\circledR}$ software in order to validate the theoretical results.

The simulation system consists of 3 modules.

In this section, simulations results are presented to illustrate the performance and robustness of proposed controls law, and the IT2FLC is applied to the DFIM with the speed control. The DFIM used in this work is a $0.8 \mathrm{~kW}$, whose nominal parameters are reported in Table 2.

The speed and flux regulation performance using the proposed IT2FLC is checked in terms of load torque variations. The motor is operated at $157 \mathrm{rad} / \mathrm{s}$ under no load; then a load disturbance torque of $5 \mathrm{~N} \cdot \mathrm{m}$ is suddenly applied at $t=0.6 \mathrm{~s}$ and eliminated at $t=1.6 \mathrm{~s}(-5 \mathrm{~N} \cdot \mathrm{m})$. The simulation results obtained for a load variation $(\mathrm{Cr}=5 \mathrm{~N} \cdot \mathrm{m},-5 \mathrm{~N} \cdot \mathrm{m})$ in Figures 7,8 , and 9 show that the speed, the torque, and the flux are inflated with this variation. Indeed the torque and the speed follow their reference values.

In order to verify the robustness of the regulator under motor parameters variations we carried out a test for a variation of $50 \%$ in the value of stator resistance at tile $t=$ $1.5 \mathrm{~s}$. The speed is fixed at $157 \mathrm{rad} / \mathrm{s}$ and a resistant torque of

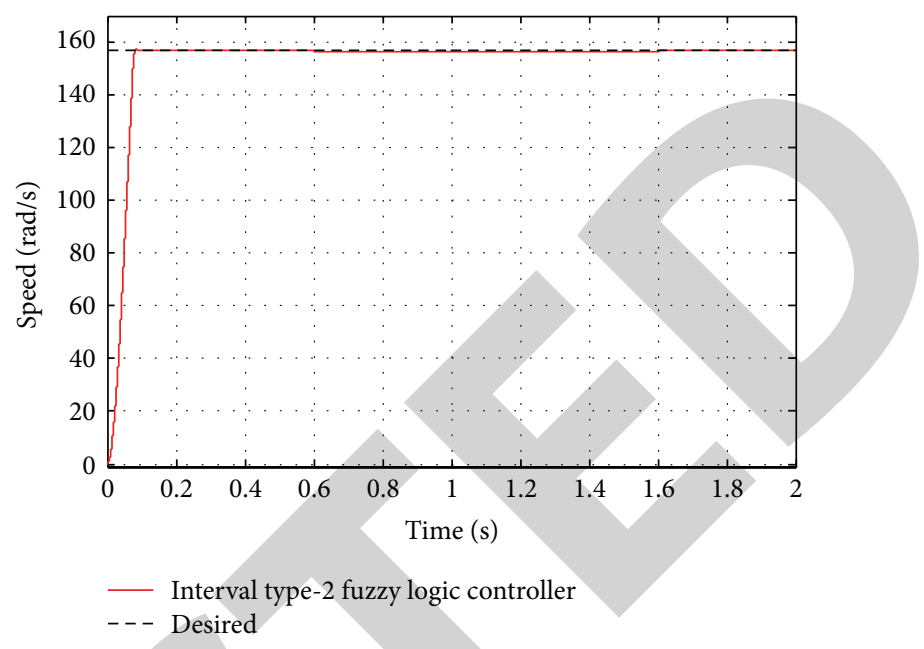

FIgURE 7: Result of speed under a load $\mathrm{Cr}=5 \mathrm{~N} \cdot \mathrm{m}$ in the interval [0.6 Sec-1.6 Sec].

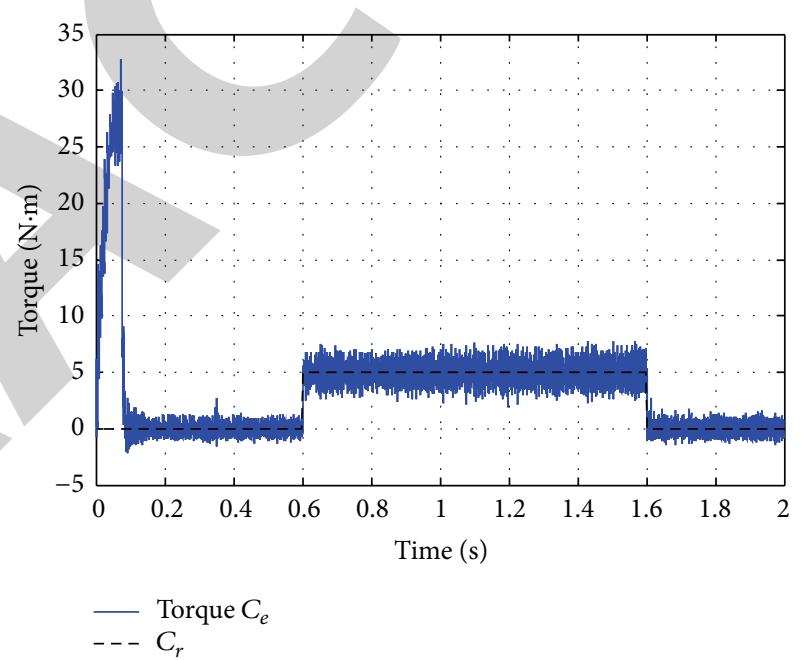

FIgURE 8: Result of torque under a load $\mathrm{Cr}=5 \mathrm{~N} \cdot \mathrm{m}$ in the interval [0.6 Sec-1.6 Sec].

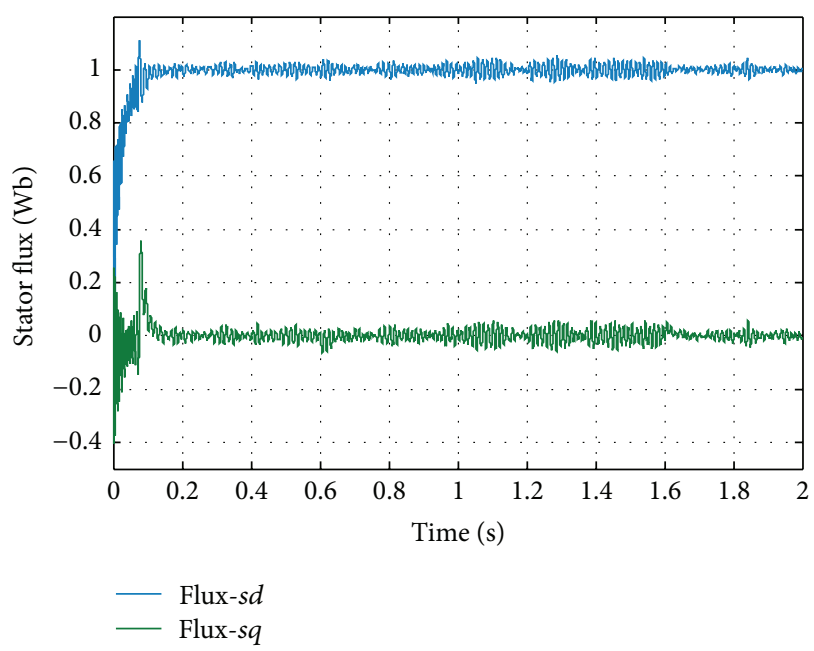

FIGURE 9: Result of stator flux under a load $\mathrm{Cr}=5 \mathrm{~N} \cdot \mathrm{m}$ in the interval $[0.6 \mathrm{Sec}-1.6 \mathrm{Sec}]$. 


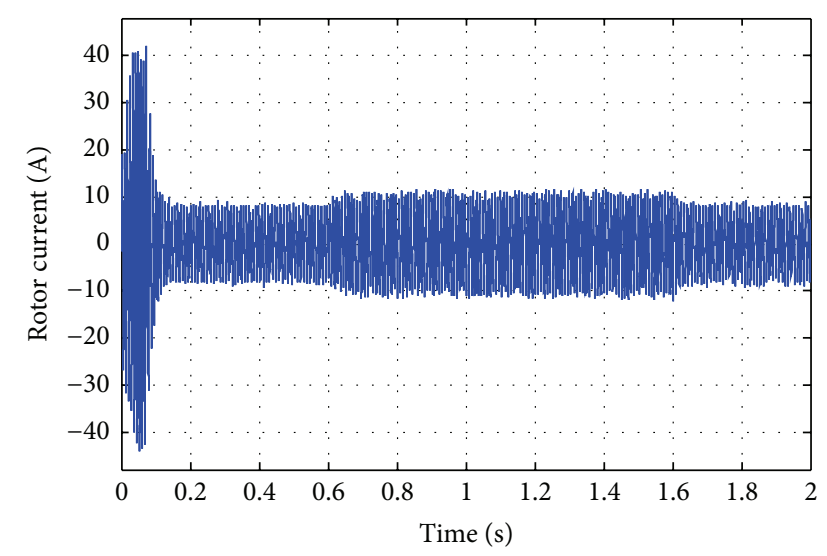

FIGURE 10: Result of rotor current under a load $\mathrm{Cr}=5 \mathrm{~N} \cdot \mathrm{m}$ in the interval [0.6 Sec-1.6 Sec].

$5 \mathrm{~N} \cdot \mathrm{m}$ is applied at $t=12 \mathrm{~s}$. Figure 6 shows, in order, the torque response, the current, the stator flux, and the speed. The results indicate that the regulator is very sensitive to the resistance change which results in the influence on the torque and the stator flux.

The responses of speed, torque, stator flux, and rotor current are shown in Figures 7, 8, 9, and 10; the IT2FLC shows good performances to achieve tracking of the desired trajectory.

As can be seen from the response of speed (Figure 7), the IT2FLC throws out the load disturbance very rapidly with no overshoot and with a negligible static error while the decoupling of torque-flux is maintained in permanent mode. We can see that the control is robust from the point of view of load variation.

In order to compare the performance of interval type2 fuzzy logic regulator with another regulator in the same test, Figure 11 shows the simulated results comparison of interval type- 2 fuzzy logic and type-1 fuzzy logic regulators of speed control of DFIM under load variation. The interval type-2 fuzzy logic controller based drive system can handle the sudden change in load torque without overshoot and undershoot and steady state error, whereas type-1 fuzzy logic controller has steady state error and the response is not as fast compared to interval type- 2 fuzzy logic controller. Thus the propose controller has been found superior to type-1 fuzzy logic controller.

The IT2FLC based drive system can handle the rapid change in load torque without overshoot and undershoot and steady state error, whereas the T1FLC has steady state error and the response is not as fast compared to the IT2FLC.

6.1. Error Tracking Performance Comparisons. These errors indexes are, namely, integral of the error (IE) and sum of the error value square (SSE). Actually these errors indexes are obtained at the end of the simulation time $(T=0.2 \mathrm{Sec})$ with

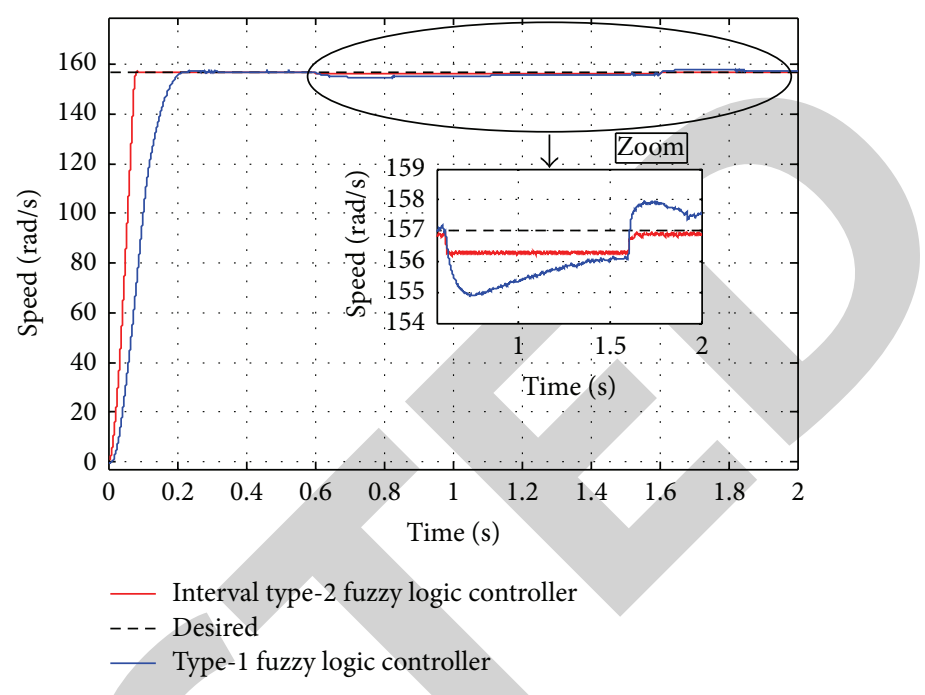

FIGURE 11: Simulated results comparison of IT2FLC and T1FLC of speed control of DFIM under load variation with zoom in the interval $[0.6 \mathrm{Sec}-2 \mathrm{Sec}]$ under a load $\mathrm{Cr}=5 \mathrm{~N} \cdot \mathrm{m}$.

TABle 3: Performance error indexes comparison.

\begin{tabular}{lcc}
\hline Controller & \multicolumn{2}{c}{ Error indexes } \\
& IE & SSE \\
\hline IT2FLC & $5.624 \times 10^{6}$ & $1.778 \times 10^{5}$ \\
T1FLC & $2.554 \times 10^{8}$ & $2.881 \times 10^{7}$ \\
\hline
\end{tabular}

a sampling period $h=0.01$. The following expressions are the definition of IE and SSE, respectively:

$$
\begin{aligned}
\mathrm{IE} & =\int_{0}^{T}\left|e_{\Omega}\right| d t, \\
\mathrm{SSE} & =0.5\left(e_{\Omega}^{T} * e_{\Omega}\right),
\end{aligned}
$$

where $e_{\Omega}$ is the tracking errors for the speed of DFIM.

Table 3 gives a quantitative comparison between the proposed IT2FLC and the T1FLC technique in load variation.

According to Table 3 it is clearly shown that the proposed IT2FLC has the smallest IE and SSE performance indexes with respect to T1FLC which prove the good tracking capabilities in both operating modes of the IT2FLC in healthy operation and variation of the parameters.

\section{Conclusion and Future Works}

In this paper a new approach for the speed control of DFIM based type-2 fuzzy logic controller is presented. To achieve our goal a mathematical model of DFIM is considered. The obtained simulation results illustrate the good performance of the proposed method in the case of load change and resistance variation torque. Such controller performs well in transient mode of DFIM and proved its robustness and its performance are less sensitive to parameters variation with respect to parametric uncertainties. In our ongoing work we are currently implementing the proposed control system in the real DFIM. 


\section{Competing Interests}

The authors declare that they have no competing interests.

\section{References}

[1] P. E. Vidal, Commande non-linéaire d'une machine asynchrone à double alimentation [Doct. Thesis], Department of Electrical Engineering, National Polytechnic Institute of Toulouse, Toulouse, France, 2004.

[2] G. Salloum, Contribution à la commande robuste de la machine asynchrone à double alimentation [Doct. thesis], Department of Electrical Engineering, National Polytechnic Institute of Toulouse, Toulouse, France, 2007.

[3] M. S. Vicatos and J. A. Tegopoulos, "A doubly-fed induction machine differential drive model for automobiles," IEEE Transactions on Energy Conversion, vol. 18, no. 2, pp. 225-230, 2003.

[4] Y. Bekakra and D. Ben Attous, "Speed and flux control for DFOC of doubly fed induction machine using sliding mode controller," Acta Electrotechnica et Informatica, vol. 10, no. 4, pp. 75-81, 2010.

[5] J. C. Prescott and B. P. Raju, "The inherent instability of induction motors under conditions of double supply," Proceedings of the IEE-Part C: Monographs, vol. 105, no. 7, pp. 319-329, 1958.

[6] E. Blaschke, "The principe of field orientation as applied to the new transvector closed loop control system for rotating field machine," Siemens Review, vol. 34, pp. 217-220, 1972.

[7] A. Chaari, M. Soltani, and M. Gossa, "Comparative study between the conventional regulators and fuzzy logic controller: application on the induction machine," International Journal on Sciences and Techniques of Automatic Control \& Computer Engineering, vol. 1, no. 2, pp. 196-212, 2007.

[8] B. Heber, L. Xu, and Y. Tang, "Fuzzy logic enhanced speed control of an indirect field-oriented induction machine drive," IEEE Transactions on Power Electronics, vol. 12, no. 5, pp. 772778, 1997.

[9] Y. Harbouche, L. Khettache, and R. Abdessemed, "Sliding mode control of the double feed asynchronous machine applied by current sources," Asian Journal of Information Technology, vol. 6, no. 3, pp. 362-368, 2007.

[10] D. Ben Attous and Y. Bekakra, "Speed control of a doubly fed induction motor using fuzzy logic techniques," International Journal on Electrical Engineering and Informatics, vol. 2, no. 3, pp. 179-191, 2010.

[11] S. Barkati, E. M. Berkouk, and M. S. Boucherit, "Application of type-2 fuzzy logic controller to an induction motor drive with seven-level diode-clamped inverter and controlled infeed," Electrical Engineering, vol. 90, no. 5, pp. 347-359, 2008.

[12] L. Benalia, "Control of a double feed and double star induction machine using direct torque control," in Torque Control, M. T. Lamchich, Ed., chapter 5, pp. 113-126, InTech, Rijeka, Croatia, 2011.

[13] N. Ezziani, Commande adaptative floue backstepping d'une machine asynchrone avec et sans capteur mecanique [Doct. Thesis in Computer Engineering, Automatic and Signal Processing], Reims University, Reims, France, 2010.

[14] M. Machmoum, F. Poitiers, L. Moreau, M. E. Zaim, and E. Le Doeuff, "Etude d'éolienne à vitesse variable basées sur des machines asynchrones (MAS-MADA)," GE44, Polytechnic Institute of Nantes, Nantes, France, 2003.
[15] A. Farrokh Payam and M. Jalalifar, "Robust speed sensorless control of doubly-fed induction machine based on input-output feedback linearization control using a sliding-mode observe," World Applied Sciences Journal, vol. 10, no. 11, pp. 1392-1400, 2010.

[16] J. M. Mendel, Uncertain Rule-Based Fuzzy Logic Systems: Introduction and New Directions, Prentice Hall, Upper Saddle River, NJ, USA, 1st edition, 2001.

[17] O. Castillo and P. Melin, "A review on interval type-2 fuzzy logic applications in intelligent control," Information Sciences, vol. 279, pp. 615-631, 2014.

[18] L. A. Zadeh, "The concept of a linguistic variable and its application to approximate reasoning-I," Information Sciences, vol. 8, pp. 199-249, 1975.

[19] R. John and S. Coupland, "Type-2 fuzzy logic: a historical view," IEEE Computational Intelligence Magazine, vol. 2, no. 1, pp. 5762, 2007.

[20] Q. Liang and J. M. Mendel, "Interval type-2 fuzzy logic systems: theory and design," IEEE Transactions on Fuzzy Systems, vol. 8, no. 5, pp. 535-550, 2000.

[21] J. M. Mendel, R. I. John, and F. Liu, "Interval type-2 fuzzy logic systems made simple," IEEE Transactions on Fuzzy Systems, vol. 14 , no. 6, pp. 808-821, 2006.

[22] H. A. Hagras, "A hierarchical type-2 fuzzy logic control architecture for autonomous mobile robots," IEEE Transactions on Fuzzy Systems, vol. 12, no. 4, pp. 524-539, 2004. 